\title{
La Régénération Naturelle Assistée (RNA) comme un moyen de reverdir le bassin arachidier au Sénégal : cas du terroir de Khatre $S y$
}

\author{
Marcel BADJI ${ }^{1 *}$, Diaminatou SANOGO ${ }^{2}$, Lamine COLY $^{3}$, \\ Youssouph DIATTA ${ }^{3}$ et Léonard Elie AKPO ${ }^{1}$ \\ ${ }^{1}$ Laboratoire d'Ecologie Végétale et d'Ecohydrologie (Ucad/Fst), BP 5005 Dakar, Sénégal. \\ ${ }^{2}$ Isra-Centre National de Recherche Forestière (Cnrf), BP 2312 Dakar, Sénégal. \\ ${ }^{3}$ Université Assane SECK de Ziguinchor, Département d'Agroforesterie, Sénégal. \\ *Auteur correspondant ; E-mail : badjimarcel@yahoo.fr
}

\section{RESUME}

Au Sénégal, le bassin arachidier est confronté à une réduction de la couverture végétale exposant les sols à l'érosion éolienne et hydrique, à la baisse de la fertilité des sols, à la rareté du bois de chauffe. Face à cette situation, les populations ont réagi dans le terroir de Khatre Sy avec l'appui du Projet de Reboisement Villageois du Nord Bassin Arachidier (PREVINOBA) en faisant la Régénération Naturelle Assistée (RNA). Cette étude évalue l'impact de la RNA sur le reverdissement du terroir de Khatre Sy. Les résultats d'inventaire montrent la présence de dix-sept espèces appartenant à onze familles dominées par les Combretaceae et les Balanitaceae. L'analyse de variance des paramètres structuraux indique une différence significative entre les arbres de la parcelle mise en défens et ceux des champs avec RNA pour le diamètre moyen du tronc et leur hauteur moyenne. Dans la mise en défens, la fréquence des arbres répond à une distribution en « $\mathrm{L}$ » décroissante, alors que, pour celle des champs avec RNA, il s'agit d'une distribution «en cloche ». L'ensemble du terroir de Khatre Sy présente une bonne capacité de régénération. La RNA a permis d'améliorer la densité des arbres dans les champs ouvrant de bonnes perspectives pour le reverdissement du bassin arachidier. (c) 2015 International Formulae Group. All rights reserved.

Mots clés : Régénération naturelle assistée, reverdissement, bassin arachidier, Sénégal.

\section{INTRODUCTION}

Au Sénégal, le bassin arachidier, qui a été pendant longtemps la zone de monoculture arachidière, est confronté à un accroissement démographique conduisant à l'extension des terres de culture et une intensification des prélèvements de bois. Cela a abouti à la réduction de la couverture végétale et à la dégradation de l'environnement exposant les sols à l'érosion éolienne et hydrique et conduisant à la baisse de la fertilité des sols, à la rareté du bois de chauffe. Cela se manifeste par des vents violents en début de saison des pluies qui détruisent les cultures après semis. Face à cette situation, les populations ont réagi en 1992 dans le terroir de Khatre Sy avec l'appui du Projet de Reboisement Villageois du Nord Bassin Arachidier (PREVINOBA) en faisant la RNA. 
Par définition la RNA est une technique agroforestière qui consiste à protéger et gérer ou entretenir les semis et repousses naturels (pousses) que produisent les souches d'arbres et d'arbustes dans les champs (Botoni et al., 2010; Larwanou et al., 2010 ; Maazou et al., 2011 ; Samaké et al., 2011). Elle permet de lutter contre les érosions hydrique et éolienne (Leenders, 2006) qui peuvent être diminuées et contribue au maintien et/ou à la restauration de la fertilité du sol (Samaké et al., 2011). Aussi, la mise en défens est une technique qui consiste à mettre au repos, par des rotations périodiques, des surfaces dégradées afin d'y favoriser la régénération des couvertures végétales et pédologiques (Badji et al., 2014). C'est dans ce contexte que ce travail a été initié. Il vise à déterminer l'impact de la RNA sur le reverdissement du terroir de Khatre Sy.

\section{MATERIEL ET METHODES}

\section{Site de l'étude}

L'étude a été réalisée dans le terroir de Khatre Sy situé au Nord-Est du Bassin arachidier précisément dans la région de Thiès, département de Tivaouane, arrondissement de Mérina Niakhène et communauté rurale Niakhène (Coly et Diatta, 2011).

Le climat de l'arrondissement de Mérina Niakhène est de type soudano sahélien caractérisé par une longue saison sèche (novembre à juin) et une courte saison des pluies (juillet à octobre). La moyenne des températures annuelles est de $26,4^{\circ}$ avec un maximum qui peut atteindre $34^{\circ}$ et un minimum de $19^{\circ}$ (Zeroual, 2005). Les précipitations sur une série de trente ans se situent en moyenne à $446 \mathrm{~mm}$ par an. Durant cette période, se sont succédées des années dont la pluviométrie est inférieure à la moyenne (1980, 1982, 1983, 1984, 1985, 1986, 1990, 1991, 1992, 1993, 1994, 1996, 1997, 1998, 2002, 2003, 2004, 2006) (Figure 1).
Le relief est relativement plat. Les principaux types de sols rencontrés sont les sols Dior (70\% des superficies cultivables), les sols Deck et Deck Dior (25\%) et les sols de bas fonds (3 à 5\%). La végétation est composée d'une strate arborée, d'une strate arbustive et d'une strate herbacée. Les espèces végétales les plus rencontrées dans la région sont Adansonia digitata, Borassus flabellifer, Faidherbia albida, Acacia seyal, Acacia tortilis et Acacia ataxacantha (Samba, 2001). $\mathrm{La}$ faune recèle diverses espèces. On $\mathrm{y}$ rencontre des lièvres, des perdrix, des chats sauvages et beaucoup d'oiseaux et de reptiles.

$\mathrm{Du}$ point de vue économique, l'agriculture occupe une place importante et constitue la première activité de la population (Semis, 2007). Elle est de type traditionnelle, extensive et sous pluies. Cependant, elle reste caractérisée par une fluctuation des emblavures et par la dégradation des sols due à une longue monoculture arachidière. Les productions agricoles sont fortement dépendantes de la pluviométrie et de la disponibilité des intrants. Les principales cultures sont les céréales, l'arachide, les cultures horticoles et fruitières. L'élevage constitue la seconde activité après les cultures. Il est basé sur un système traditionnel extensif et sédentaire. Selon ce système, les bêtes pâturent librement en saison sèche sur l'ensemble du terroir villageois et sont conduites en hivernage, sous la surveillance des bergers dans les secteurs maintenus temporairement en jachère.

\section{Diagnostic participatif}

Cette étape a consisté à identifier les différents systèmes de gestion du terroir. Pour cela, une assemblée villageoise a été tenue avec les différentes tranches d'âges pour faire la carte du terroir permettant de situer les différents systèmes de gestion du terroir de Khatre Sy (Photos 1 et 2). 


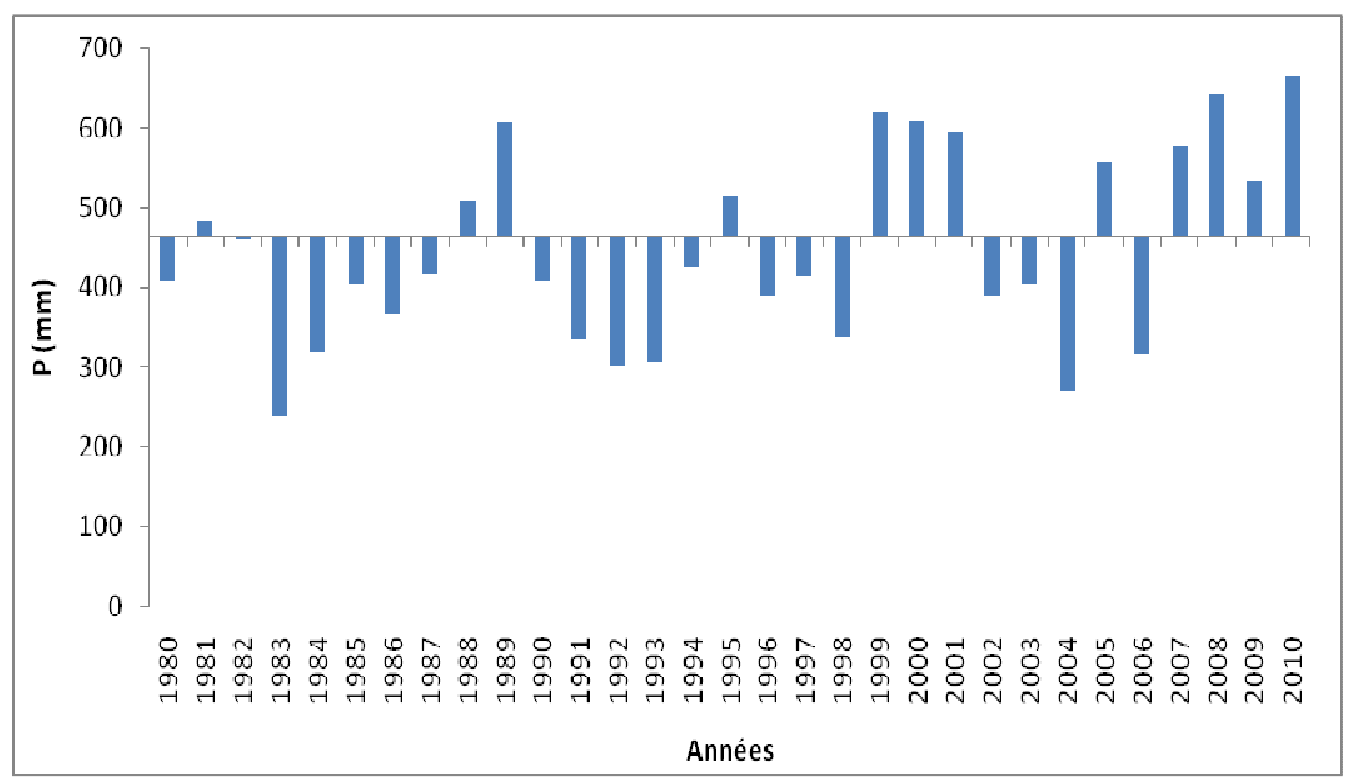

Figure 1. Données pluviométriques de la période 1980-2010 de la région de Thiès. (Source de données: Direction de la Météorologique Nationale, Sénégal ; données exprimées en écarts annuels (barres) à la moyenne de la série (446 mm).

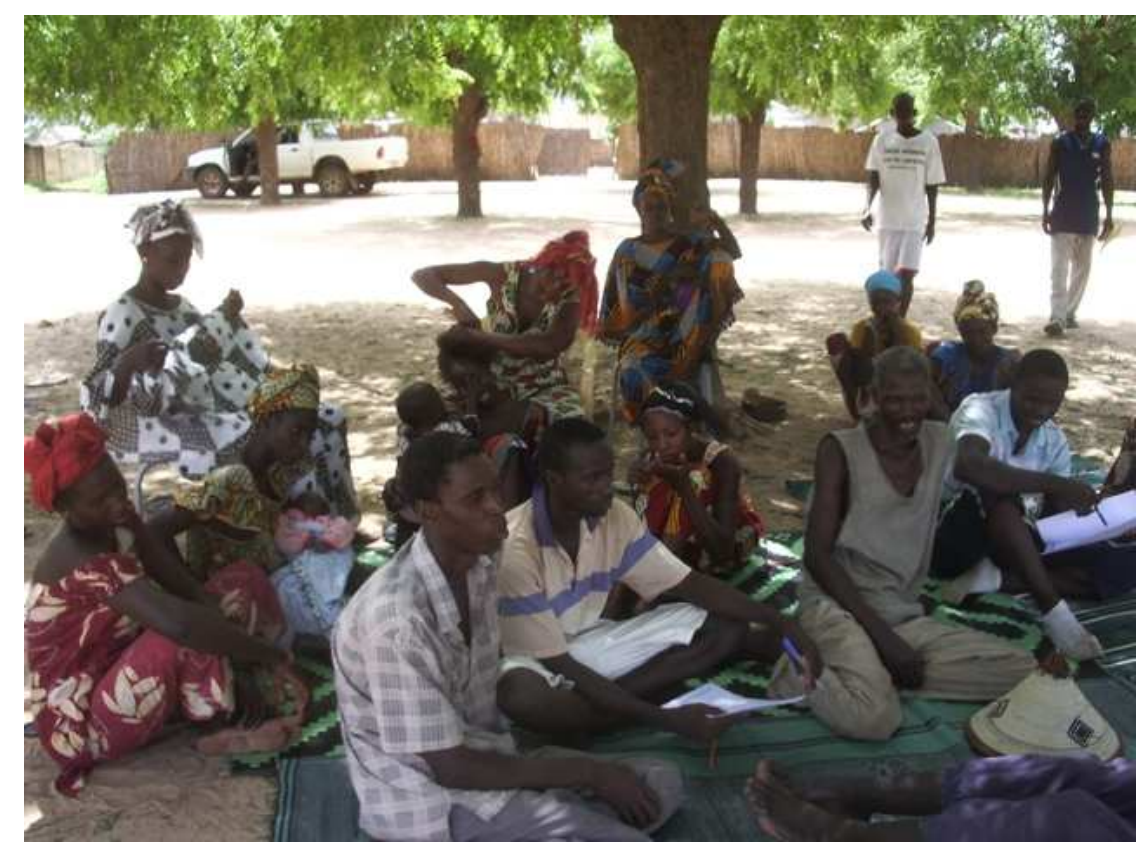

Photo 1 : Assemblée villageoise. 


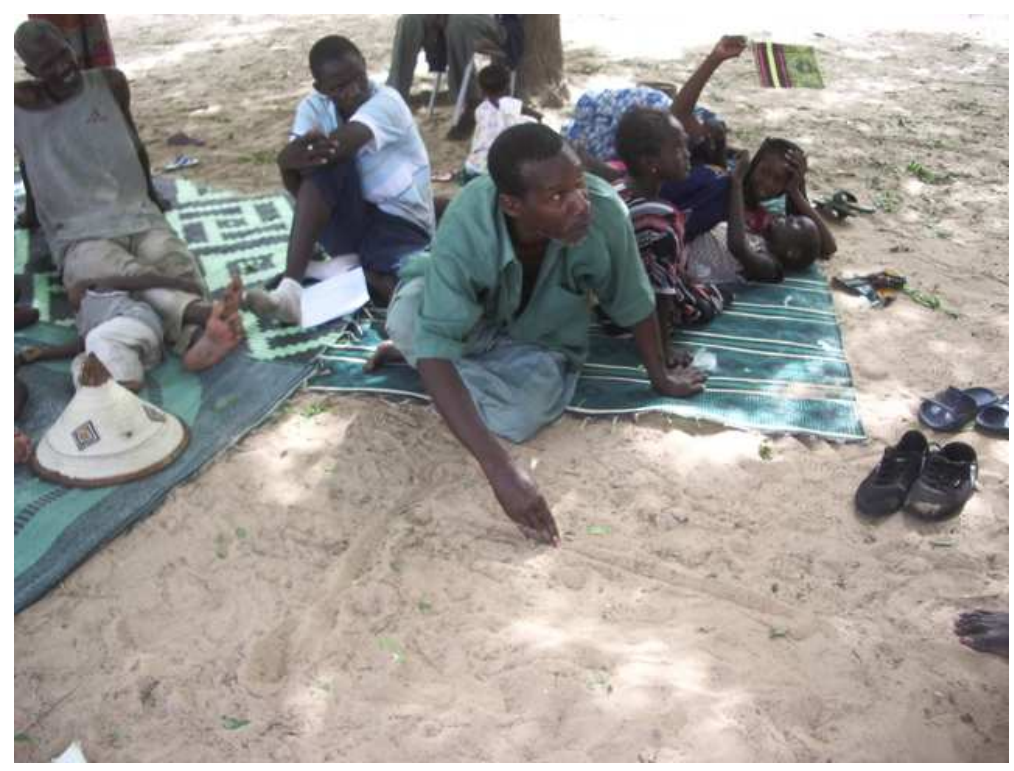

Photo 2 : Producteur indiquant les limites du terroir de Khatre Sy.

\section{Collecte de données}

Les données pour évaluer l'impact de la régénération naturelle ont été obtenues par inventaires forestiers dans la mise en défens et dans les champs de RNA. Les unités d'observation sont des placettes de $900 \mathrm{~m}^{2}$ (30 $\mathrm{m}$ x $30 \mathrm{~m}$ ) délimités le long des transects à des intervalles réguliers de $50 \mathrm{~m}$ (Boudet, 1984). Les mesures effectuées portent sur les caractéristiques dendrométriques (diamètre à $30 \mathrm{~cm}$ du sol, hauteur totale) de tous les arbres présents dans les placettes. Le diamètre des arbres a été mesuré avec un compas forestier et la hauteur totale avec une perche graduée de $8 \mathrm{~m}$. Le potentiel de régénération a été apprécié par le comptage des individus dont le diamètre est inférieur à $3,5 \mathrm{~cm}$ soit $10 \mathrm{~cm}$ de circonférence selon Sokpon et al. (2006). Au total, 162 placettes ont été effectuées ainsi répartis : 80 dans la mise en défens et 82 dans les champs.

\section{Analyse et traitement de données}

Les paramètres structuraux retenus pour caractériser les peuplements dans la mise en défens et les champs étudiées sont la densité, le diamètre moyen, la surface terrière et la hauteur totale des individus. La densité d'un peuplement ligneux exprime le nombre total d'arbres par unité de surface (hectare). La surface terrière $\left(\mathrm{en} \mathrm{m}^{2} / \mathrm{ha}\right)$ a été calculée suivant la relation :

$$
\mathrm{G}=\pi \mathrm{d}^{2} / 4 \text {; avec } \mathrm{G} \text { en } \mathrm{m}^{2} / \mathrm{ha} \text { et } \mathrm{d}
$$
exprimant le diamètre à $0,3 \mathrm{~m}$.

La comparaison des paramètres structuraux (diamètre moyen, densité, surface terrière, hauteur) entre les deux zones a été réalisée par analyse de variance (ANOVA) grâce au programme Xlstat. Le test de comparaison des moyennes de Fisher a été effectué pour dégager les degrés de signification des différences entres les moyennes observées entre les zones. Les différentes structures (structure en diamètre et répartition par classe de hauteur) ont permis d'établir l'abondance relative des arbres par classe de diamètre et de hauteur. La densité de régénération est exprimée en nombre de rejets par unité de surface (hectare). Elle a permis de calculer l'indice de régénération (IR) qui 
résulte du rapport de la densité de régénération sur densité des arbres adultes et renseigne sur le niveau de la régénération et peut orienter les interventions à effectuer sur le parc (Samaké et al., 2011).

\section{RESULTATS}

Cartographie participative du terroir de Khatre Sy

Le terroir de Khatre Sy a une superficie de 392 ha. Il est constitué des champs de culture avec la RNA d'une superficie d'environ 290 ha, de la zone mise en défens (57,05 ha) situé au nord Ouest du village, du périmètre maraîcher et $\mathrm{du}$ bois villageois (Figure 2). La zone mise en défens est constituée d'anciens champs que les propriétaires ont abandonnés à cause de la baisse de la fertilité et qui sert d'espace de pâturage pour les populations du village de Khatre Sy. Elle a été mise en défens en 2008.

\section{Diversité des espèces ligneuses du terroir de Khatre Sy}

Les inventaires effectués dans le terroir de Khatre Sy (mise en défens et champs avec RNA) ont permis d'identifier 17 espèces ligneuses réparties en 11 familles. Le Tableau 1 reprend la répartition des espèces et genres aux différentes familles. Combretaceae, Balanitaceae et Asclepiadaceae sont les familles les plus abondantes. Les relevés effectués montrent que, parmi les Combretaceae, Combretum glutinosum et Guiera senegalensis sont les espèces les plus abondantes. Au niveau de la diversité spécifique et générique, 13 genres et 14 espèces ont été recensés dans la mise en défens contre 10 genres et 12 espèces dans les champs à RNA.

\section{Caractéristiques dendrométriques}

De l'analyse du Tableau 2, il ressort que le diamètre moyen, la hauteur moyenne et la surface terrière sont plus élevés dans les champs avec RNA. Le fait que le diamètre moyen et la surface terrière soient plus élevés dans les champs avec RNA montre que les populations de Khatre Sy ont toujours laissé les arbres dans leurs champs qui permettent soit une amélioration de la fertilité des sols, soit qui leur fournissent des produits qu'elles utilisent pour l'alimentation ou qui sont vendus. L'analyse statistique révèle qu'il y a une différence significative entre la densité et le diamètre moyen des arbres de la mise en défens et ceux des arbres de champs avec RNA. Il en est de même pour la hauteur moyenne $(\mathrm{P}<0,0001)$.

\section{Répartition selon le diamètre}

La Figure 3 présente la distribution par classe de diamètre de la mise en défens et des champs à RNA. On distingue deux types de structures:

- Type 1: distribution décroissante en «L» (Figure 3 a) : Dans la mise en défens, la distribution des arbres par classe de diamètre montre une allure en «L» indiquant que les basses classes de diamètre (diamètre $\leq 10 \mathrm{~cm}$ ) sont mieux représentées que les gros individus avec 23 individus/ha (Photo 3).

- Type 2: distribution en cloche (Figure 3 b) : Dans les champs à RNA, la distribution des arbres par classe de diamètre montre une allure en cloche, indiquant qu'il existe des classes intermédiaires (diamètre]10$15 \mathrm{~cm}]$ ) mieux représentées que les extrêmes. Cela peut s'expliquer par les coupes des rejets dans les champs avec RNA lors de la préparation des champs.

\section{Répartition selon la hauteur}

La Figure 4 montre la structure verticale du peuplement ligneux des deux zones. Dans la mise en défens comme dans les champs avec RNA, l'essentiel des ligneux est groupé dans les classes de [2-4[et [4-6[. Ils 
représentent des densités 36 arbres/ha dans la mise en défens contre 17 arbres/ha dans les champs avec RNA du total des individus recensés. Les individus à hauteur supérieure à $6 \mathrm{~m}$ représentent 8 individus/ha et 10 individus/ha pour la mise en défens et les champs avec RNA respectivement. La strate ligneuse de la zone d'étude est donc arbustive.

\section{Régénération}

Le Tableau 3 révèle la densité et l'indice de régénération dans la mise en défens et dans les champs à RNA. On constate que la densité dans la mise en défens est le double de celle des champs à RNA. Cela peut s'expliquer par le fait que dans les champs, les populations utilisent la charrue pour cultiver. Ce qui nécessite beaucoup d'espaces. Aussi dans ces deux zones, on note un indice de régénération supérieur à 1 traduisant un peuplement en pleine reconstitution.

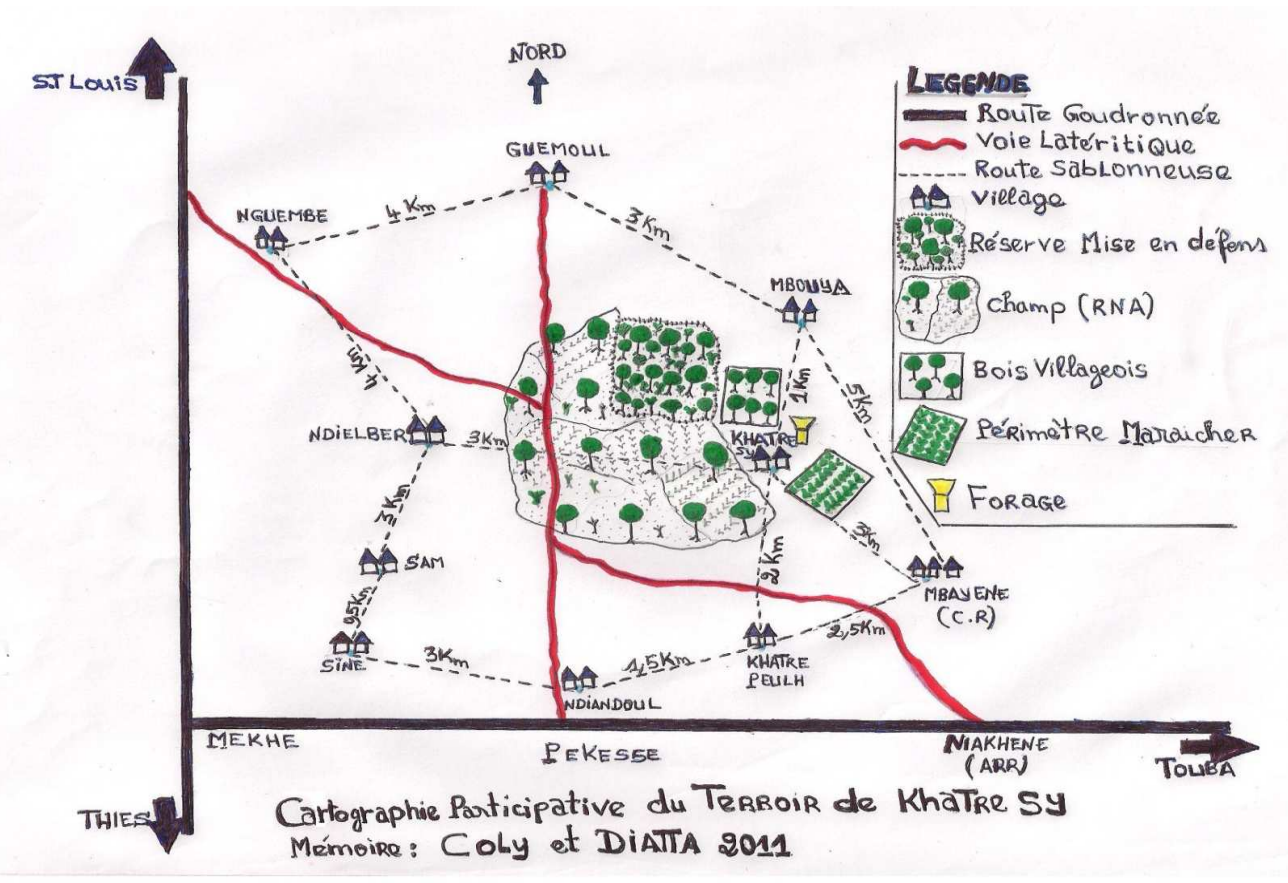

Figure 2 : Carte du terroir de Khatre Sy. 

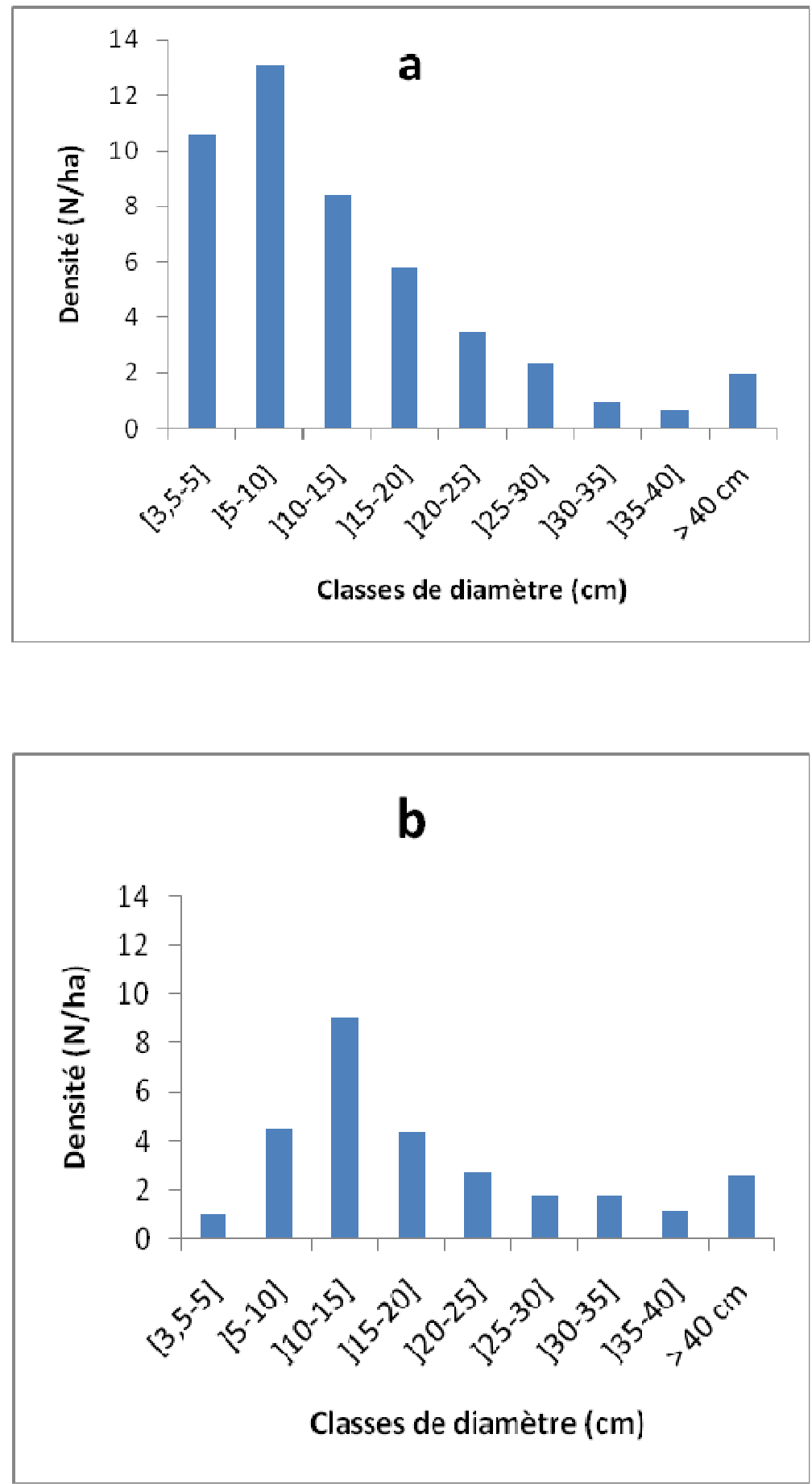

Figure 3: Structure diamétrique de la mise en défens (a) et des champs à RNA (b). 


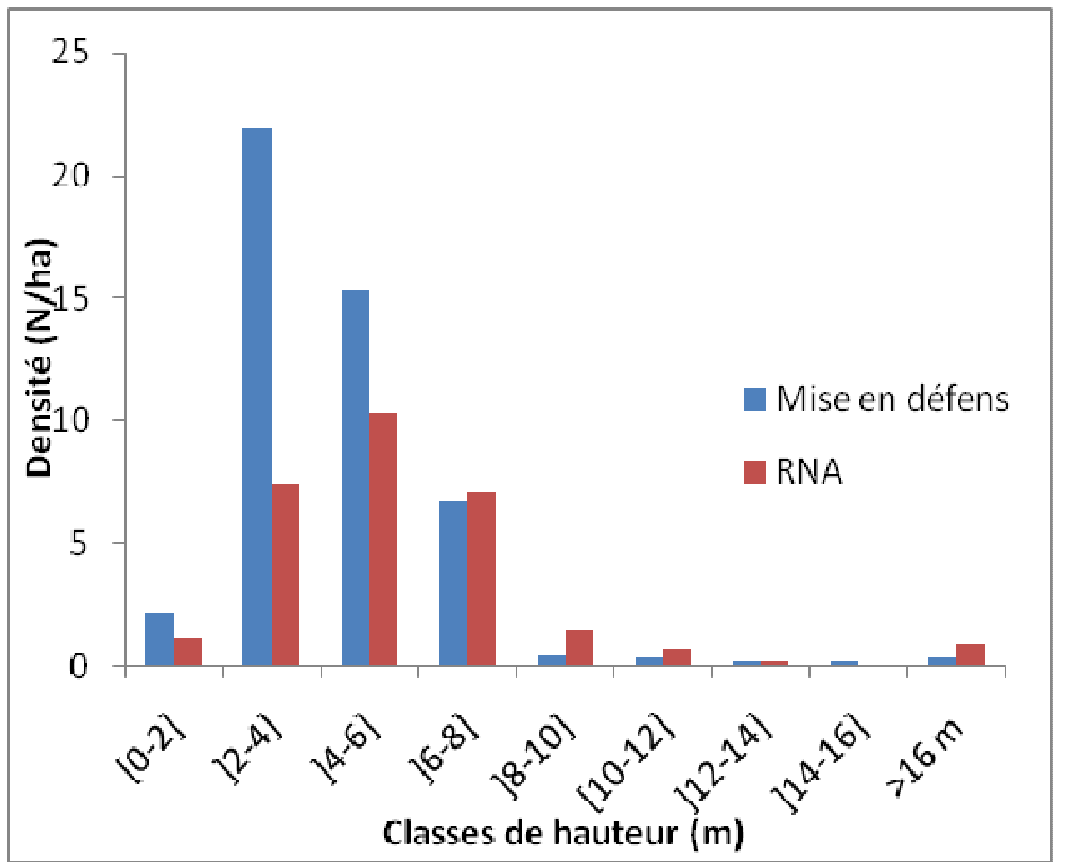

Figure 4 : Structure verticale du peuplement ligneux du terroir de Khatre Sy.

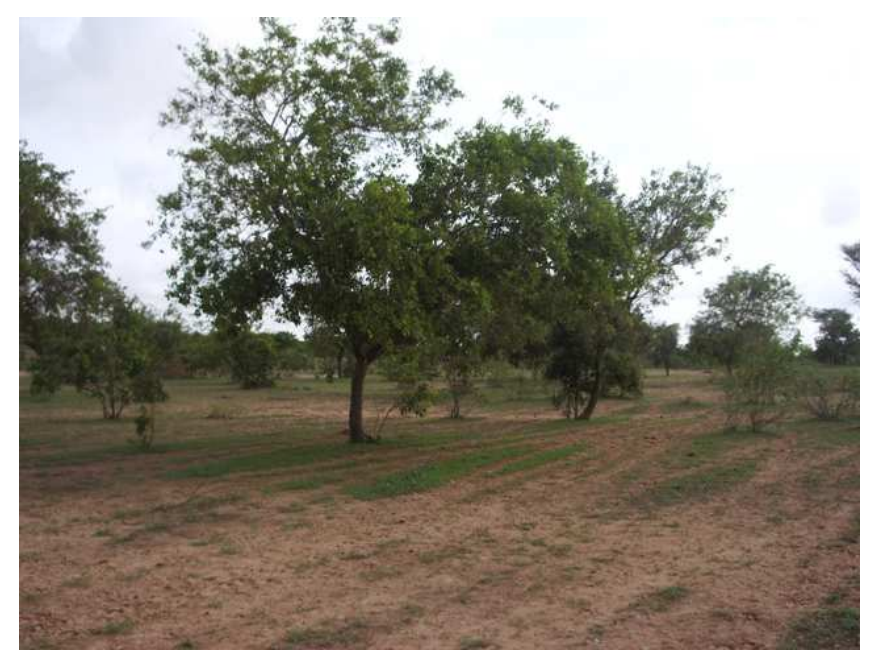

Photo 3 : Arbres dans la mise en défens. 


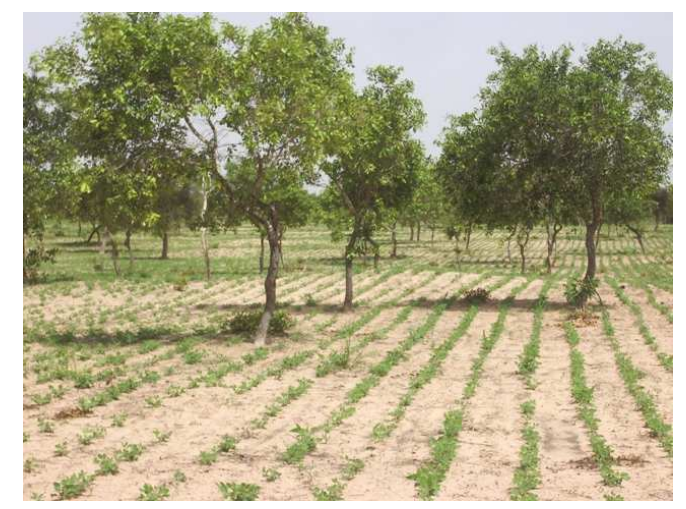

Photo 4 : Parc à Combretum glutinosum.

Tableau 1 : Répartition des espèces au sein des différentes familles.

\begin{tabular}{lcccccc}
\hline Familles & \multicolumn{3}{c}{ Mise en défens } & \multicolumn{3}{c}{ Champs à RNA } \\
\cline { 2 - 7 } & Nb. genres & Nb. espèces & $\mathbf{F ~ ( \% ) ~}$ & $\begin{array}{c}\text { Nb. } \\
\text { genres }\end{array}$ & $\begin{array}{c}\text { Nb. } \\
\text { espèces }\end{array}$ & F (\%) \\
\hline Annonaceae & 1 & 1 & 0,22 & 1 & 1 & 0,36 \\
Asclepiadaceae & 1 & 1 & $\mathbf{1 7 , 1 2}$ & 1 & 1 & $\mathbf{7 , 8 5}$ \\
Balanitaceae & 1 & 1 & $\mathbf{3 1 , 9 5}$ & 1 & 1 & $\mathbf{2 4 , 7}$ \\
Bombacaceae & - & - & - & 1 & 1 & 0,3 \\
Burseraceae & 1 & 1 & 0,06 & - & - & - \\
Caesalpiniaceae & 1 & 1 & 0,06 & - & - & - \\
Capparaceae & 2 & 2 & 0,09 & 1 & 1 & 0,36 \\
Celastraceae & 1 & 1 & 0,13 & - & - & - \\
Chrysobalanaceae & 1 & 1 & 0,13 & 1 & 1 & 0,24 \\
Combretaceae & 2 & 3 & $\mathbf{4 8 , 3 1}$ & 2 & 3 & $\mathbf{6 3 , 7 7}$ \\
Mimosaceae & 2 & 2 & 1,9 & 2 & 3 & 2,35 \\
Total & 13 & 14 & 100 & 10 & 12 & 100 \\
\hline
\end{tabular}

Tableau 2 : Valeurs des moyennes des différents paramètres dendrométriques des arbres dans les champs à RNA et dans la zone mise en défens.

\begin{tabular}{lcc}
\hline Paramètres dendrométriques & Champs & Mise en défens \\
\hline Densité $(\mathrm{N} / \mathrm{ha})$ & $29 \mathrm{a}$ & $49 \mathrm{~b}$ \\
Diamètre moyen $(\mathrm{cm})$ & $22,26 \pm 2,1 \mathrm{~b}$ & $14,01 \pm 0,63 \mathrm{a}$ \\
Hauteur moyenne $(\mathrm{m})$ & $5,89 \pm 0,25 \mathrm{~b}$ & $4,4 \pm 0,12 \mathrm{a}$ \\
Surface terrière $\left(\mathrm{m}^{2} / \mathrm{ha}\right)$ & 23,71 & 8,71 \\
\hline
\end{tabular}

Tableau 3 : Densité et l'indice de régénération dans la mise en défens et les champs avec RNA.

\begin{tabular}{lcc}
\hline & Mise en défens & RNA \\
\hline Densité (N/ha) & 394 & 195 \\
IR & 8,3 & 6,72 \\
\hline
\end{tabular}




\section{DISCUSSION}

La flore ligneuse du terroir de Khatre Sy est riche de 17 espèces dominées par les Combretaceae (Combretum glutinosum et Guiera senegalensis) et les Balanitaceae. Ces espèces régénèrent vite (Dossa et al., 2009) en donnant beaucoup de rejets après les coupes (Diédhiou et al., 2009 ; Diack et al., 2000) et ne sont pas dessouchées par les paysans à cause de leurs usages multiples (Boffa, 2000). La faible diversité de la zone d'étude résulte des défrichements intensifs ajoutés aux conditions climatiques plus défavorables qui ont fait disparaître les espèces qui ne supportent pas les coupes répétées. Selon Taita (2003), la plupart des espèces en déclin sont parmi celles appréciées et plus utilisées par les populations. Par contre, dans le site étudié, les Combretaceae à forte capacité de régénération sont parmi les plus utilisées notamment en pharmacopée et comme bois de chauffe. Ce qui fait apparaître un nouveau parc dominé par ces dernières (Photo 4).

L'étude des caractéristiques dendrométriques montre que la densité des ligneux dans la mise en défens est supérieure à celle des champs à RNA. Cela peut s'expliquer par l'élimination de rejets dans les champs pour faciliter la traction animale lors du labour. Dans les champs de RNA, les producteurs ont recours aux pratiques telles que les coupes, l'élagage et le labour. Cellesci jouent un rôle dans la diminution de la densité de régénération. Ce qui se traduit par une densité de régénération plus importante dans la mise en défens. La présence de souches permet de maintenir dans les parcelles pendant la phase de culture un potentiel de ligneux qui favorise le retour des arbres après abandon cultural. En plus des coupes, la pratique du labour contribue à la diminution de la régénération. Selon Samaké et al. (2011) la régénération naturelle est plus favorisée dans les champs cultivés à la houe (63 plants/ha) que dans les champs travaillés à la charrue (9 plants/ha). De même, cette densité de régénération est plus forte dans les champs éloignés du village (champ de brousse) (236 souches/ha) et sur les sols lourds (182 souches/ha sur sol sablo-argileux) contre 90 souches/ha sur sol sablonneux. Mais la plupart des espèces dont les rejets sont annuellement coupés et brûlés sont parmi ceux qui sont considérés abondantes dans les parcelles de culture (Faye et al., 2008). Par ailleurs, la densité des champs avec RNA est supérieure à celle trouvée par Bakhoum (2012) dans les systèmes agraires (17 pieds/ha) de la région de Kaffrine. Ce qui montre l'importance de la RNA dans le reverdissement du terroir de Khatre Sy.

Dans la mise en défens, la structure selon le diamètre est de type exponentiel décroissant traduisant une végétation en reconstitution. Beaucoup d'auteurs expliquent ce phénomène par la capacité de régénération du peuplement (Mbayngone et al., 2008 ; Dan Guimbo et al., 2010; Thiombiano et al., 2010 ; Vinke et al., 2010). Par contre, la tendance en cloche observée dans les champs à RNA pourrait être le fait des défrichements et du maintien dans les champs des arbres qui permettent une amélioration de la fertilité des sols ou fournissent des produits qui sont utilisés dans l'alimentation ou vendus. Ce qui se traduit par une surface terrière plus élevée dans les champs à RNA révélant la présence de gros arbres épargnés par les agriculteurs et qui jouent un rôle important dans la fertilisation des sols (cas de Faidherbia albida, Adansonia digitata). $\mathrm{Ce}$ résultat corrobore celui de plusieurs auteurs qui affirment que le choix des espèces à épargner dans les champs concourt à l'élargissement de la gamme de produits et services émanant des arbres mais aussi fait intervenir des considération d'ordre socioculturelle qu'économique (Boffa, 2000 ; Bakhoum et al., 2001 ; Akpo et al., 2004 ; Kizito et al., 2006 ; Larwanou et al. 2006; Rinaudo, 2010 ; Samaké et al., 2011).

En guise de conclusion, cette étude a mis en évidence l'impact de la RNA sur le reverdissement du Nord bassin arachidier. Elle a montré que la RNA a permis d'améliorer les caractéristiques 
dendrométriques (diamètre, hauteur, densité) des arbres dans les champs ouvrant de bonnes perspectives pour le reverdissement à moindre coût du bassin arachidier.

\section{REMERCIEMENTS}

Ce travail a été possible grâce au financement du projet « Renforcement des stratégies locales de gestion des espaces sylvo-pastoraux intervillageois $\mathrm{du}$ Bassin arachidier (Sénégal) », financé par le Crdi.

\section{REFERENCES}

Akpo LE, Coly I, Sarr D, Ngom D, Ndao S. 2004. Modes d'utilisation des terres et diversité floristique dans le terroir de la Néma en zone semi-aride (Sénégal, Afrique de l'Ouest). Journal of Agriculture and Environment for International Development, 98(3/4): 165180.

Badji M, Sanogo D, Akpo LE. 2014. Dynamique de la végétation ligneuse des espaces sylvo-pastoraux villageois mis en défens dans le Sud du Bassin arachidier au Sénégal. Bois et Forêts des Tropiques, 319(1): 43-52.

Bakhoum C, Samba ANS, Ndour B. 2001. Sterculia setigera Del.: effet sur les culures. Ann. For. Sci. 58: 207-215.

Bakhoum C. 2012. Diversité et capacités de régénération naturelle du peuplement ligneux dans les systèmes agraires du bassin arachidier en zone soudanosahélienne (région de Kaffrine, Sénégal). Thèse de doctorat en Biologie, Physiologie et productions végétales, UCAD/FST, p. 154.

Boffa JM. 2000. Les parcs agroforestiers en Afrique de l'Ouest : clés de conservation et d'une gestion durable. Unasylva, 51(200): 11-17.

Botoni E, Larwanou M, Reij C. 2010. La régénération naturelle assistée (RNA): une opportunité pour reverdir le Sahel et réduire la vulnérabilité des populations rurales. Le Projet majeur africain de la
Grande Muraille Verte, Concepts et mise en œuvre, 151-162.

Boudet G. 1984. Manuel et Précis d'Elevage, Manuel sur les Pâturages Tropicaux et les Cultures Fourragères (4 ${ }^{\text {ème }}$ édn). Ministère de la Coopération : Paris ; 254.

Coly L, Diatta Y. 2011. Régénération Naturelle Assistée et Mise en défens: Adoption et conséquences écologiques dans le terroir de Khatre Sy (Bassin Arachidier du Sénégal). Mémoire Licence Agroforesterie, Université de Ziguinchor, p. 37.

Dan Guimbo I, Mahamane A, Ambouta KJM. 2010. Peuplement des parcs à Neocarya macrophylla (Sabine) Prance et à Vitellaria paradoxa (Gaerth.C.F) dans le sud-ouest nigérien: diversité, structure et regeneration. International Journal of Biological and Chemical Sciences 4(5): 1706-1720.

Diack M, Sène M, Badiane AN, Diatta M, Dick RP. 2000. Decomposition of a native shrub, Piliostigma reticulatum, litter in soils of semiarid Senegal. Arid Soil Res. Rehabil. 14: 205-218.

Diedhiou S, Dossa EL, Badiane AN, Diedhiou I, Sène M, Dick RP. 2009. Decomposition and spatial microbial heterogeneity associated with native shrubs in soils of agroecosystems in semiarid Senegal. Pedobiologia, 52: 273286.

Dossa EL, Khouma M, Diedhiou I, Sène M, Kizito F, Badiane AN, Samba SAN, Dick RP. 2009. Carbon, nitrogen and phosphorus mineralization potential of semiarid Sahelian soils amended with native shrub residues. Geoderma, 148: 251-260.

Faye E, Diatta M, Samba ANS, Lejoly J. 2008. Usages et dynamique de la flore ligneuse dans le terroir villageois de Latmingué (Sénégal). Journal des Sciences et Technologies, 7: 43 -58.

Kizito F, Dragila M, Sène M, Lufafa A, Diédhiou I, Dick RP, Selker JS, Dossa E, Khouma M, Badiane A, Ndiaye S. 2006. 
Seasonal soil water variation and root patterns between two semi-arid shrubs co-existing with Pearl millet in Senegal, West Africa. Journal of Arid Environments, 67: 436-455.

Larwanou M, Abdoulaye M, Reij C. 2006. Etude de la Régénération Naturelle Assistée dans la Région de Zinder (Niger). USAID/EGAT: Niger; 56.

Larwanou M, Oumarou L, Laura, Snook, Danguimbo I. 2010. Pratiques sylvicoles et culturales dans les parcs agroforestiers suivant un gradient pluviométrique nordsud dans la région de Maradi au Niger. Tropicultura, 28(2): 115-122.

Leenders JK. 2006. Wind erosion control with scattered vegetation in the Sahelian zone of Burkina Faso. Tropical Ressource Management Papers, $\mathrm{N}^{\circ}$ 73. PhD Thesis Wageningen University, p. 184.

Maazou S, Souleymane, Kennedy, Wema M. 2011. Forêts, préserver l'or vert. Spore, 153: 13-17.

Mbayngone E, Thiombiano A, Hahn-Hadj ali K, Guinko S. 2008. Structure des ligneux des formations végétales de la Réserve de Pama (Sud-Est du Burkina Faso, Afrique de l'Ouest. Flora et Vegetatio SudanoSambesica, 11: 25-34.

Rinaudo T. 2010. Une brève histoire de la régénération naturelle assistée, l'expérience du Niger. Echo, Note technique. 27p.

Samba ANS. 2001. Etude cas du projet de reboisement villageois dans le Nord-ouest $\mathrm{du}$ basin arachidier (PREVINOBA). Atelier régional sur les aspects socioéconomiques de l'agroforesterie au sahel,
5-8 Décembre 2000, SEGOU- MALI ; 12-14.

Samaké O, Dakouo JM, Kaliganie A, Bayala J, Kone B. 2011. Régénération Naturelle Assistée-Gestion des Arbres Champêtres au Sahel, Technical Manual. ICRAF. World Agroforestry Centre: Nairobi; 40.

Sokpon N, Biaou SH, Ouinsavi C, Hunhyet O. 2006. Bases techniques pour une gestion durable des forêts claires du Nord-Bénin : rotation, diamètre minimal d'exploitabilité et régénération. Bois et Forêts des Tropiques, 287: 45-57.

Semis. 2007. Plan local d'hydraulique et d'assainissement (PLHA). Communauté Rurale de Niakhène. 26p.

Taita P. 2003. Use of woody plants by locals in Mare aux Hippopotames Biosphère Réserve in western Burkina Faso. Biodiversity and Conservation 12: 12051217.

Thiombiano DNE, Lamien N, Dibong SD, Boussim IJ. 2010. Etat des peuplements des espèces ligneuses de soudure des communes rurales de Pobé-Mengao et de Nobéré (Burkina Faso). Journal of Animals \& Plant Sciences, 9(1): 11041116.

Vinke C, Diédhiou I, Grouzis M. 2010. Long term dynamics and structure of woody vegetation in the Ferlo (Senegal). Journal of Arid Environment, 74 : 268-276.

Zeroual K. 2005. Etude et réalisation d'un système d'information géographique pour le réseau d'assainissement de la ville de Thiès. Mémoire de diplôme d'Ingénieur de conception. UCAD, p. 64. 